NBER WORKING PAPER SERIES

\title{
MORE BAD NEWS FOR SMOKERS? THE EFFECTS OF CIGARETTE SMOKING ON LABOR MARKET OUTCOMES
}

Phillip B. Levine

Tara A. Gustafson

Ann D. Velenchik

Working Paper 5270

\section{NATIONAL BUREAU OF ECONOMIC RESEARCH 1050 Massachusetts Avenue \\ Cambridge, MA 02138 \\ September 1995}

The authors would like to thank Jon Gruber and Doug Staiger for useful comments and discussions and Wellesley College for financial support. This paper was written while Levine was on leave from Wellesley and in residence at the National Bureau of Economic Research. This paper is part of NBER's research programs in Health Economics and Labor Studies. Any opinions expressed are those of the authors and not those of the National Bureau of Economic Research.

(C) 1995 by Phillip B. Levine, Tara A. Gustafson and Ann D. Velenchik. All rights reserved. Short sections of text, not to exceed two paragraphs, may be quoted without explicit permission provided that full credit, including $\odot$ notice, is given to the source. 


\title{
MORE BAD NEWS FOR SMOKERS? THE EFFECTS OF CIGARETTE SMOKING ON LABOR MARKET OUTCOMES
}

\begin{abstract}
This paper uses data from the National Longitudinal Survey of Youth to examine the effect of smoking on wages and employment. The panel nature and household structure of these data enable us to implement methods to account for differences in observed and unobserved individual characteristics that may be correlated with both smoking and wages. Changes in wages associated with changes in smoking behavior and models that utilize sibling comparisons are estimated to address the potential heterogeneity problem. Estimates from alternative specifications all indicate that smoking reduces wages by roughly $4-8 \%$. No robust, statistically significant effect on employment is observed.
\end{abstract}

Phillip B. Levine

Department of Economics

Wellesley College

Wellesley, MA 02181

Ann D. Velenchik

Department of Economics

Wellesley College

106 Central Street

Wellesley, MA 02181
Tara A. Gustafson

Brattle/IRI

44 Brattle Street

Cambridge, MA 02138 


\section{Introduction}

Since the release of the 1964 Surgeon General's report asserting that smoking causes cancer and other serious diseases, evidence of the adverse health effects of smoking, both on smokers and on others who are exposed to cigarette smoke, has continued to mount. Over time, mild public intolerance of smoking has developed into fairly widespread hostility. More recent public policy in this area has been designed to protect non-smokers from second hand smoke (Office of Technology Assessment, 1986). Policies enacted at the federal, state, and local levels of government include the federal ban on smoking on domestic airline flights and state and municipal regulations banning or restricting smoking in government buildings, private workplaces, bars and restaurants. Moreover, many employers have instituted their own smoking policies banning smoking in buildings or restricting it to designated areas. The Oklahoma City fire department even maintains a "non-smokers only" employment policy that has been upheld by a federal court.

This hostility towards those who smoke may translate into worse labor market outcomes for these workers. If employers, coworkers or customers dislike smokers, discrimination against smokers, which would reduce their wages and employment prospects, could result.

Discrimination is not the only reason one may expect smokers to perform less well in the labor market, however. Smoking may reduce net worker productivity. For instance, in those environments where smoking is restricted to certain areas, smokers would have to leave their workplaces to smoke, resulting in less time on the job and lower productivity. Smoking may also interfere with workers' ability to carry out manual tasks. Smokers may also be more costly as employees, due to increased absenteeism, higher health and fire insurance premia, higher maintenance costs, and negative effects on morale. ${ }^{1}$ Finally, the health problems associated with smoking may lead smokers to have a preference for jobs that include employer-provided

${ }^{1}$ In fact, studies examining the additional costs incurred from employing a smoker estimate this cost at roughly $\$ 1,000$ annually (Kristein, 1983; Bertera, 1991). 
health insurance. A compensating differentials model would indicate that better health insurance would be associated with lower wages, and hence we would observe smokers earning less.

The goal of this paper is to provide empirical evidence regarding the effects of smoking on wages and employment. Statistically, the central issue is to disentangle the effects of smoking on wages and employment from the effects of observed and unobserved personal characteristics which may be correlated with both smoking behavior and labor market outcomes. Using data from the National Longitudinal Survey of Youth (NLSY), we employ three techniques directed at addressing this issue. Initially, we estimate a standard, cross-sectional, human capital earnings function (Willis, 1986) including a dummy variable indicating whether an individual smokes along with an extensive set of personal and family background measures as well as an individual's performance on an aptitude/achievement test. In addition, we use the panel nature of the NLSY data to estimate changes in wages as a function of changes in smoking behavior over time, therefore controlling for any person-specific characteristics that are constant over time. Finally, we take advantage of the household structure of the NLSY, comparing the difference in outcomes between siblings who differ in their smoking behavior. This approach controls for unobservable characteristics that are constant within a family. Our results indicate that smoking reduces wages by roughly $4-8 \%$ across all the specifications. No robust, statistically significant effect of smoking on employment is observed.

\section{Review of Related Literature}

To our knowledge, no study examining the relationship between smoking and labor market outcomes has been conducted. There are related literatures, however, that have explored the labor market effects of other personal behaviors or attributes, such as drug and alcohol use 
and body weight. ${ }^{2}$ A brief review of these areas of research motivates the issues raised and methodology employed in the current research.

In much of this work, the challenge is to separate the effects of the attribute from the effects of other personal characteristics that are correlated with both the attribute and labor market outcomes. ${ }^{3}$ One method for doing this is to formally treat the behavior in question (e.g. alcohol or drug use) as endogenous, estimate a "use function," and apply the use function in statistical models that adjust for sample selection. For instance, in studies of the effects of drug use, Kaestner (1991) uses a two stage least squares technique, while Register and Williams (1992) and Gill and Michaels (1992) both use Heckman (1979) style corrections. Berger and Leigh (1988) use a similar technique in analyzing the effect of alcohol use on wages.

A second method is to control for unobservable characteristics using fixed effect methods based on difference techniques. In their study of the effect of body weight on income, Averett and Korenman (1993) use differences between same-sex siblings to control for social class and family background characteristics which may influence both body weight and economic outcomes. ${ }^{4}$

\section{Methodology}

This section will set forth the methodology that we employ to determine the effects of smoking on labor market outcomes. The discussion is centered around the effects on wages,

${ }^{2}$ Personal attractiveness is another attribute that may influence labor market outcomes, and its effects have been explored in Hamermesh and Biddle (1994). Although the issue is similar to drug or alcohol use or body weight, the problem of controlling for unobservables in this case seems somewhat less important.

${ }^{3}$ Some recent papers on the labor market consequences of alcohol use (Mullahy and Sindelar, 1993) and body weight (Costa, 1994 and Gruber and Kubik, 1994) do not attempt to account for this endogeneity.

${ }^{4} \mathrm{~A}$ similar difference based technique looks at differences in an individual's behavior over time rather than differences across siblings. We will use both techniques in this paper. 
although straightforward extensions would apply to an analysis of the effects on employment. We omit these here for the purposes of simplicity of exposition and notation.

One approach to analyzing the wage effects of smoking is simply to include a dummy variable for smoking behavior in OLS regressions incorporating a full range of human capital, personal characteristic and family background variables. This regression takes the form:

$$
\ln \mathrm{W}_{\mathrm{i}}=\alpha+\mathrm{X}_{\mathrm{i}} \beta_{1}+\mathrm{F}_{\mathrm{i}} \beta_{2}+\mathrm{S}_{\mathrm{i}} \beta_{3}+\mathrm{e}_{\mathrm{i}}
$$

where $W_{i}$ represents wages, $X_{i}$ is a vector of observed individual characteristics, $F_{i}$ is a vector of family background characteristics, and $S_{i}$ is an indicator variable which takes the value of unity if the individual is a smoker and zero otherwise. The coefficient, $\beta_{3}$, would then be interpreted as the wage consequences of smoking.

This approach is problematic if there are unobserved characteristics of individuals which are correlated with smoking and with wages, but uncorrelated with the other independent variables in the equation. In that event, the estimate of $\beta_{3}$ will be biased. For example, if people with poor judgement are likely to choose to smoke, and no measure of judgement is included in the regression, the estimate of $\beta_{3}$ will be biased downward, as the negative wage consequences of having poor judgement would be attributed to the act of smoking instead. One simple mechanism for dealing with this issue is to include as regressors measures which may be correlated with relevant unobservables. One potential measure is the individual's score on an aptitude/achievement test, such as the Armed Forces Qualifying Test (AFQT) available in the NLSY. This approach has been used by Blackburn and Neumark (1993) using the NLSY data examining the returns to education. To the extent that test scores capture otherwise unobservable productivity-related characteristics, they can reduce the downward bias on the smoking coefficient. 
It is also possible, of course, that smokers are different from nonsmokers in ways that are not correlated with test scores or other observable characteristics. One approach to account for the effects of this unobservable heterogeneity is to apply panel data techniques. Examining the relationship between changes in wages and changes in smoking behavior over time would control for characteristics of the individual that are constant over time. More formally, equation (1) can be modified to represent an individual's wages in time period t:

$$
\ln \mathrm{W}_{\mathrm{it}}=\alpha+\mathrm{X}_{\mathrm{it}} \beta_{1}+\mathrm{F}_{\mathrm{i}} \beta_{2}+\mathrm{S}_{\mathrm{it}} \beta_{3}+\gamma_{\mathrm{i}}+\mathrm{e}_{\mathrm{it}}
$$

where $\gamma_{i}$ represents an individual-specific component of an individual's wage that is time invariant (an "individual fixed effect"). If information is available for two periods, then differencing these data across periods yields:

$$
\Delta \ln \mathrm{W}_{\mathrm{it}}=\Delta \mathrm{X}_{\mathrm{i}} \beta_{1}+\Delta \mathrm{S}_{\mathrm{i}} \beta_{3}+\Delta \mathrm{e}_{\mathrm{i}}
$$

Estimates of this model will provide unbiased estimates of $\beta_{3}$ even in the presence of individual fixed effects.

An alternative means of obtaining estimates of the effects of smoking behavior potentially unbiased by unobserved characteristics is to exploit the household structure of the NLSY by looking at differences in wages and smoking behavior across siblings. This technique is similar to that used by Averett and Korenman (1993) in their discussion of the effect of weight on earnings, discussed above, and Ashenfelter and Zimmerman (1995) to estimate the returns to education. To the extent that unobserved characteristics are correlated across siblings, this technique will produce unbiased estimates of the effects of smoking. ${ }^{5}$

${ }^{5}$ Ashenfelter and Zimmerman show that this type of fixed effects specification cannot be distinguished from a correlated random effects estimate in a sibling wage difference model. 
These estimates can be generated both in single cross-sections, or by "stacking" multiple years of data. The latter approach is advantageous relative to using a single year because the additional data improve the precision of all coefficient estimates, although standard errors need to be adjusted to correct for repeated observations on each sibling pair. In addition, observations in which siblings' smoking behavior is the same may be included to provide more precise estimates of the other parameters in the model. These advantages have been neglected in some recent work exploiting sibling differences.

The model we estimate is formally expressed as:

$$
\ln \mathrm{W}_{\mathrm{o}}-\ln \mathrm{W}_{\mathrm{y}}=\alpha+\left(\mathrm{X}_{\mathrm{o}}-\mathrm{X}_{\mathrm{y}}\right) \beta_{1}+\left(\mathrm{S}_{\mathrm{o}}-\mathrm{S}_{\mathrm{y}}\right) \beta_{2}+\mathrm{e}_{\mathrm{oy}}
$$

where all notation is the same as above except that $\mathrm{o}$ indexes the older sibling and $\mathrm{y}$ indexes the younger. As in the individual fixed effect model represented by equations (2) and (3), if unobserved family-specific characteristics ("family fixed effects") are assumed constant between siblings, taking differences between siblings, as in equation (4), will eliminate this family fixed effect. Therefore, the coefficient, $\beta_{2}$, measures the effects of smoking behavior on wages or employment after controlling for differences in unobservable family background characteristics.

An alternative approach for dealing with the selectivity issues surrounding smoking behavior would estimate an instrumental variables model using an instrument that is correlated with an individual's smoking behavior, but uncorrelated with his/her wages. We explored two alternative sets of instruments, neither of which performed adequately. The first was to use the cigarette excise tax rate in the individual's state of residence at age 14 as an instrument for smoking. Since most people start smoking as teenagers, if there is some price elasticity of demand for starting smoking, we would expect that smoking would be negatively correlated with tax rates. The tax rates turned out to be a very weak instrument, however, because their 
correlation with a teenagers' decision to start smoking is quite low in the NLSY data ${ }^{6}$ A second alternative was the use of state fixed effects as instruments that could pick up differences in the environment regarding smokers and smoking in different states. First stage regression results indicate that these variables provide "weakly correlated instruments" which, as has been pointed out by Staiger and Stock (1994), yield second stage parameter estimates which are biased towards the OLS estimates. We therefore do not report results of an instrumental variables model.

\section{Data}

The analysis uses data from the National Longitudinal Survey of Youth (NLSY). The NLSY is an ongoing study of 12,686 men and women who were between the ages of 14 and 21 when they were first interviewed in 1979. These data supply a wealth of information for each respondent including labor market behavior, demographic characteristics, and family background characteristics. By 1992, these individuals range in age from 27 to 34, and have largely entered the labor force.

Most important for the purposes of this project are the smoking questions that were asked of respondents in the 1984 and 1992 surveys." The definition of a "smoker" is somewhat different between the two surveys, however, because the format of the questions asked is

${ }^{6}$ Mullahy and Sindelar (1995) experience similar problems using state tax data as instruments in estimating the employment consequences of problem drinking. Their IV estimates generate a 10 fold increase in standard errors relative to their OLS estimates.

${ }^{7}$ The 1992 survey also includes retrospective data on smoking that could allow us to implement an approach similar to that implied by equation (3). These data can be used to identify the effect of smoking on wages by comparing wages before and after quitting smoking for those workers who quit during the panel. Unfortunately, these data appear to be measured with a substantial degree of error. For example, estimates of the model represented by equation (2) can be obtained using reported smoking behavior in 1984 or by using the retrospective smoking history data for that year. Estimates using the retrospective data provided much lower estimated effects of smoking on wages, indicating the presence of measurement error bias. For this reason, we do not report our attempts at estimating models using these data. 
different. In 1992, a "smoker" is defined as someone who reports that s/he currently smokes daily. ${ }^{8}$ In the 1984 survey, smokers are defined as those respondents who report smoking at least one cigarette per day, on average, over the last 30 days. These definitions may lead to some false transitions in smoking status between 1984 and 1992 if some respondents "binge" say, on weekends, smoking large numbers of cigarettes a few days a month.

Because individuals are surveyed early in the calendar year, the last full year of labor market data included in the 1992 round of the NLSY was for calendar year 1991. We use two additional smoking questions asked in 1992 to define smoking status in the preceding year. Starting from the respondent's smoking status in 1992, we recode this variable using responses to questions regarding the year a respondent started or quit smoking. This approach provides an additional advantage because it avoids misclassifying the large number of smokers in 1992 who report that they have just quit smoking, even though most of them probably quit only temporarily. ${ }^{9}$ Therefore, our second cross-section of data represents workers in the year 1991 . In addition, the wage analysis using both 1984 and 1991 data will include only full-year full-time workers earning more than $\$ 100$ per week in 1991 dollars in order to avoid entangling issues

${ }^{8}$ Although the survey instrument allows individuals to identify themselves as occasional smokers, preliminary analysis indicated that occasional smoking exerts no significant influence on wages, and we therefore treat occasional smokers as non-smokers. In addition, current daily smokers are asked the number of cigarettes they smoke per day. We find that wages are unaffected by smoking intensity once we control for whether an individual smokes daily.

${ }^{9}$ In the 1992 survey, at least four times as many respondents report quitting smoking in the past year than in any preceding year. 
of labor force participation and employment in our discussion of the wage effects of smoking. ${ }^{10}$ All NLSY respondents are included in our analysis of employment. ${ }^{11}$

Descriptive statistics for these data are presented in Tables 1 through 3. The data in Table 1 show a decline in the incidence of smoking, from $35 \%$ of the sample in 1984 to $29 \%$ in 1991. There is a large wage differential associated with smoking in both years, with smokers earning $11 \%$ less on average in 1984 , and $18 \%$ less in 1991 . Smokers and non-smokers also differ in several observable characteristics that may explain this differential. Most important, smokers have substantially less education on average than do non-smokers. This education gap widened from eight-tenths of a year in 1984 to nearly a year and a half in 1991 . The change in this gap is probably attributable to the fact that many respondents had not finished their schooling in 1994, and non-smokers were more likely to continue their education than were smokers. Many of the other characteristics listed in the table are consistent with the difference in earnings between smokers and non-smokers: smokers have lower AFQT scores, less educated parents and are more likely to live in the South than are non-smokers. The data also show an employment differential associated with smoking: smokers worked an average of 75 fewer hours per year in 1984, and 162 fewer in 1991.

${ }^{10}$ Full-time, full-year workers are defined as those who have worked at least 50 weeks and 1750 hours in a calendar year. Other sample restrictions were made because of missing demographic and family background characteristics. For instance, in 1991, sample attrition and responses to the smoking questions reduces the sample to roughly 8,500. Missing demographic data eliminates about another 1,000 observations, of which about one-third did not have an AFQT score. Another 1,000 respondents were missing data on family background characteristics, of whom over two-thirds were missing data on parent's education. The full-time, full-year sample restriction lowered the sample size to the final level of 3,473 .

${ }^{11}$ In models of employment using data from 1984, we restrict the sample to include those respondents who are over age 21 . The reason for this restriction is that the employment of people younger than this is likely to be mechanically correlated with schooling decisions (i.e. if one drops out of school early, s/he is more likely to get a full-time, full-year job). Because schooling is so strongly correlated with smoking, we have chosen those respondents over age 21 since the vast majority have completed their schooling by this point. Other sample restrictions were made because of missing data, as detailed in the preceding note. 
Average changes in characteristics of individuals between 1984 and 1991 are reported in Table 2. Statistics are reported separately depending upon the workers' smoking status in the two years. The results indicate that wages increased by about $30 \%$ for workers whose smoking status was the same in both years. In contrast, workers who quit smoking over the period experienced about a $39 \%$ wage increase. Wages of workers who started smoking between the two years increased by $28 \%$, just slightly below the level observed for continuous smokers and nonsmokers. Trends in years of education across groups between the two years are consistent with these wage trends, but these differences are so small they could not plausibly explain the differences in wage growth. Quitters were somewhat more likely to get married over the period, but again, differences are quite small compared to the differential wage growth experienced by this group. No other obvious patterns are present in any of the data, including annual hours worked.

Summary statistics for the sibling comparisons are presented in Table 3. The data for this exercise are ordered so that characteristics of younger siblings are differenced from those of older siblings. Because the effect of smoking on the wage differential depends upon whether the older sibling or younger sibling smokes, the statistics are further conditioned upon which sibling smokes. The case where both siblings have the same smoking status is included as a reference. In both years, we observe that older siblings earn more than younger siblings among those pairs with the same smoking status, as expected. In 1991, we also see that smoking by the younger sibling appears to increase the size of the wage gap while older sibling smoking reduces it. In the data for 1984, however, although smoking by the younger sibling increases the wage gap by about $16 \%$ (from $13.2 \%$ in sibling pairs with the same smoking status to $29.3 \%$ here), older sibling smoking appears to make the wage gap larger as well, by $7.5 \%$. This pattern may be attributable to the small sample sizes in the 1984 data. Overall, the wage effect of smoking in these data is negative. 
Similar comparisons of observable characteristics reported in Table 2, particularly years of education, show that differences between siblings in smoking behavior are correlated with the observed differences in these characteristics. These results largely parallel those reported in Table 1 with the important exception of annual hours worked. One would expect that older siblings work more than younger siblings in this sample of younger workers, ceteris paribus. This is indeed what we see for sibling pairs who exhibit the same smoking behavior. Based on the results in Table 1, one would expect this difference to rise (fall) if the younger (older) sibling smokes, but this is not fully apparent in the data presented in Table 2. There is no intuitive explanation for this discrepancy.

\section{Wage Results}

The results from the OLS regression in equation (1) allow us to separate out the effects of smoking from the effects of the differences in human capital, highlighted above, and other observable characteristics, including the AFQT score. These results are reported in Table 3. Columns (1) and (6) replicate the raw wage differentials presented in Table 1. The inclusion of education in the regression, reported in columns (2) and (7), substantially reduced the measured impact of smoking, to $5.7 \%$ in 1984 and $7.4 \%$ in 1991 . The addition of a full range of personal and family background characteristics, including AFQT scores, generated small additional reductions in the measured effect of smoking, as reported in the final estimates in columns (3) and (8). ${ }^{12}$ Clearly much of the effect of being a smoker is generated by differences in the educational decisions of smokers and nonsmokers rather than the smoking behavior itself. Nevertheless, after controlling for a wide array of observable characteristics, smoking is estimated to lower a worker's wage by $4-8 \%$. The other parameter estimates reported in the table correspond well to the general results in the literature.

\footnotetext{
${ }^{12}$ Inclusion of nonlinear age terms, occupation controls and state fixed effects has a very small effect on these estimates, so these results are not reported.
} 
The last two columns for each year present estimates of the effect of smoking for each gender separately. The effect of smoking on men's wages appears to be larger than the effect on women's, but this difference is only statistically significant in the 1984 sample. One potential explanation for this difference is that the wage effects of smoking are more highly concentrated in "good" jobs that are less commonly held by women.

Although the inclusion of individual characteristics in the OLS regression substantially reduces the measured effect of smoking, estimates of the differential may still be biased if unobservable characteristics are correlated with both smoking and wages. Table 4 presents the results of addressing this bias by employing panel data to estimate equation (3), for the whole sample and separately by gender. The point estimate of the effect of smoking presented in column (1), indicating a $5.4 \%$ reduction in wages associated with smoking, is similar in magnitude to the OLS estimates reported in Table 3, although it is less precisely estimated. This indicates that the OLS estimates are probably not generated primarily by differences in the unobservable characteristics of the two groups. The gender-specific effects are the opposite of those reported in Table 3, with the effect of smoking on women's, wages appearing to be larger, although the standard errors are significantly larger than those reported in Table 3 . The gender differences in the coefficients are statistically insignificant, so it is difficult to draw definitive conclusions about gender differences in the labor market consequences of smoking.

Estimates of equation (4) using the sibling data are presented in Table 5. Six versions of the sibling regression were estimated: each cross-section separately and the two years pooled for both the full sample of sibling pairs and for the subset of pairs whose smoking behavior differed. Again, the results closely parallel those arising from the OLS regressions reported in Table 3, with estimated wage effects of smoking ranging between $5.5 \%$ and $8.0 \%$, with the larger estimates for the 1991 cross-section. Pooling the data substantially increases the precision of all of the coefficient estimates, though there are no differences between the estimates generated using the whole sample relative to the subsample of pairs whose smoking behavior 
differs. Again, the similarity between these estimates and the OLS estimates indicates that there is no evidence that the OLS estimates were biased by the presence of unobservable correlates of smoking.

\section{Results for Employment}

The results for all three estimation techniques for the employment analysis are reported in Table 6. Although the summary statistics reported in Tables 1 and 2 indicated that smoking is associated with fewer hours worked, none of the results in Table 6 indicate adverse employment effects of smoking. Only the OLS estimates for 1991 presented in column (2) indicate a negative effect of smoking on employment, and this coefficient is not statistically significant. Columns (3) through (6) present estimates controlling for unobserved heterogeneity that parallel the results presented in Tables 4 and 5. The estimated relationship between changes in smoking behavior over time and changes in hours presented in column (3) actually shows a positive relationship between smoking and hours worked, although this counterintuitive result is not robust to the alternative specifications examined here. The sibling data estimates presented in columns (4) through (6) also indicate a positive effect of smoking on hours, though none of these effects are significant. Overall, these results indicate that smoking does not negatively influence the employment aspect of labor market outcomes, although the previous results indicate a significant effect on wages among those who are employed full-time.

\section{Conclusions}

This analysis has shown that smoking has a deleterious effect on smokers' wages, but does not affect their level of employment. The large wage differential observed in simple comparisons of the wages of smokers and nonsmokers strongly overstates the causal effect of smoking. Smokers clearly differ from non-smokers in a variety of ways, particularly with respect

to their levels of education, and controlling for these differences in OLS regression models 
substantially reduced the measured effect of smoking. Using additional econometric tools designed to control for unobservable characteristics that might influence smoking and wages produced virtually no change in the magnitude of this effect. We find that workers who smoke earn $4-8 \%$ less than nonsmokers after controlling for differences between the groups. Although simple comparisons seem to indicate that smokers have lower levels of employment, OLS regressions that control for differences in characteristics yield no significant difference in employment outcomes.

Although we have argued that the statistical specifications employed in this analysis address the problem of unobservable heterogeneity, potential problems with each individual method remain. Including AFQT scores may not control for all unobservable characteristics. Changes in an individual's smoking behavior over time may be correlated with other changes in an individual's life (marriage, for instance) that may be correlated with changes in wages. Differences in smoking status between siblings hold family background characteristics constant, but not differences between siblings within a family. Nevertheless, roughly consistent findings obtained from each method, all with unrelated weaknesses, strongly supports the hypothesis that smoking lowers wages.

The difference between the effect of smoking on wages and its effect on employment can be reconciled by considering the process by which individuals are hired as distinct from the process that determines their wage growth once employment is obtained. When an individual applies for a job, it is unlikely that the potential employer knows that the individual smokes, so we would not expect smokers to be less likely to gain employment than non-smokers. Once the individual is hired, however, his or her smoking is likely to become known. One possible course of action is dismissal. This would generate a negative relationship between smoking and employment, and our evidence is inconsistent with that hypothesis. A second possibility is that employers fail to promote or give raises to smokers, which would result in the effect on wages this analysis has identified. As discussed earlier, such behavior is consistent with employer 
discrimination, increased costs associated with hiring a smoker, or lower productivity exhibited by smokers. We leave an examination of the motivation underlying employer behavior to future research. ${ }^{13}$

The negative relationship between smoking and wages also raises an additional question regarding the societal costs of smoking. To the extent that this relationship can be attributed to reduced productivity or increased costs, societal resources are reduced. There are currently about 110 million workers employed nationwide, earning close to $\$ 400$ per week on average. If $30 \%$ of these workers smoke, and smoking reduces wages by, say, $5 \%$ then the societal costs associated with smoking in terms of lost output or increased expenditures are $\$ 660$ million per week or over $\$ 34$ billion per year.

${ }^{13}$ Using the NLSY we conducted an investigation regarding the extent to which the reduction in wages associated with smoking is linked to those workers receiving employer provided health insurance. Unfortunately, the results of this analysis were inconclusive due to imprecise parameter estimates on the relevant variables. 
References

Ashenfelter, Orley and Zimmerman, David J. Estimates of the Returns to Schooling from Sibling Data: Fathers, Sons, and Brothers," NBER working paper no. 4491. 1993.

Averett, Susan and Sanders Korenman. "The Economic Reality of The Beauty Myth." National Bureau of Economic Research Working Paper No. 4521, November 1993.

Berger, Mark C. and J. Paul Leigh. "The Effect of Alcohol Use on Wages." Applied Economics. Vol. 20, No. 4 (October 1988), pp. 1343-1351.

Bertera, Robert L. "The Effects of Behavioral Risks on Absenteeism and Health-Care Costs in the Workplace." Journal of Occupational Medicine. Vol. 33, No. 11 (November 1991), pp. 1119-1123.

Blackburn, M. L. and Neumark, D. "Omitted-Ability Bias and the Increase in the Return to Schooling," Journal of Labor Economics, Vol. 11, No 3 (July 1993), pp. 521-544.

Costa, Dora L. "Health and Labor Force Participation of Older Men, 1900 - 1991." National Bureau of Economic Research Working Paper No. 4929. (November, 1994).

Gill, Andrew M. and Robert J. Michaels. "Does Drug Use Lower Wages." Industrial and Labor Relations Review. Vol. 45, No. 3 (April 1992), pp. 419-434.

Gruber, Jonathan and Jeffrey D. Kubik. "Disability Insurance Rejection Rates and the Labor Supply of Older Workers." National Bureau of Economic Research Working Paper No. 4941. (November, 1994).

Hamermesh, Daniel and Jeff Biddle. "Beauty and the Labor Market." American Economic Review. Vol. 84, No. 5 (December 1994), pp. 1174-1194.

Heckman, James J. "Sample Selection Bias as a Specification Error," Econometrica, Vol. 47 (1979), pp. 153-161.

Kaestner, Robert. "The Effect of Illicit Drug Use on the Wages of Young Adults. "Journal of Labor Economics. Vol 9, No. 4 (October 1991), pp. 381-412.

Kristein, Marvin M. "How Much can Business Expect to Profit from Smoking Cessation?" Preventive Medicine. Vol. 12 (1983), pp. 358-381.

Mullahy, John and Jody L. Sindelar. "Alcoholism, Work, and Income." Journal of Labor Economics. Vol. 11. No. 3 (July 1993), pp. 494-520.

Mullahy, John and Jody L. Sindelar. "Employment, Unemployment, and Problem Drinking." National Bureau of Economic Research Working Paper No. 5123. (May, 1995).

Office of Technology Assessment, U.S. Congress. "Passive Smoking in the Workplace: Selected Issues." staff paper, May 1986. 
Register, Charles A. and Donald R. Williams. "Labor Market Effects of Marijuana and Cocaine Use Among Young Men." Industrial and Labor Relations Review. Vol. 45, No. 3 (April 1992), pp. 435-448.

Staiger, Douglas and James H. Stock. "Instrumental Variables Regression with Weak Instruments." National Bureau of Economic Research Technical Working Paper No. 151. (January 1994).

Willis, Robert J. "Wage Determinants: A Survey and Reinterpretation of Human Capital Earnings Functions," in Orley Ashenfelter and Richard Layard (eds.) Handbook of Labor Economics, Volume 1. Amsterdam: North Holland, 1986. 


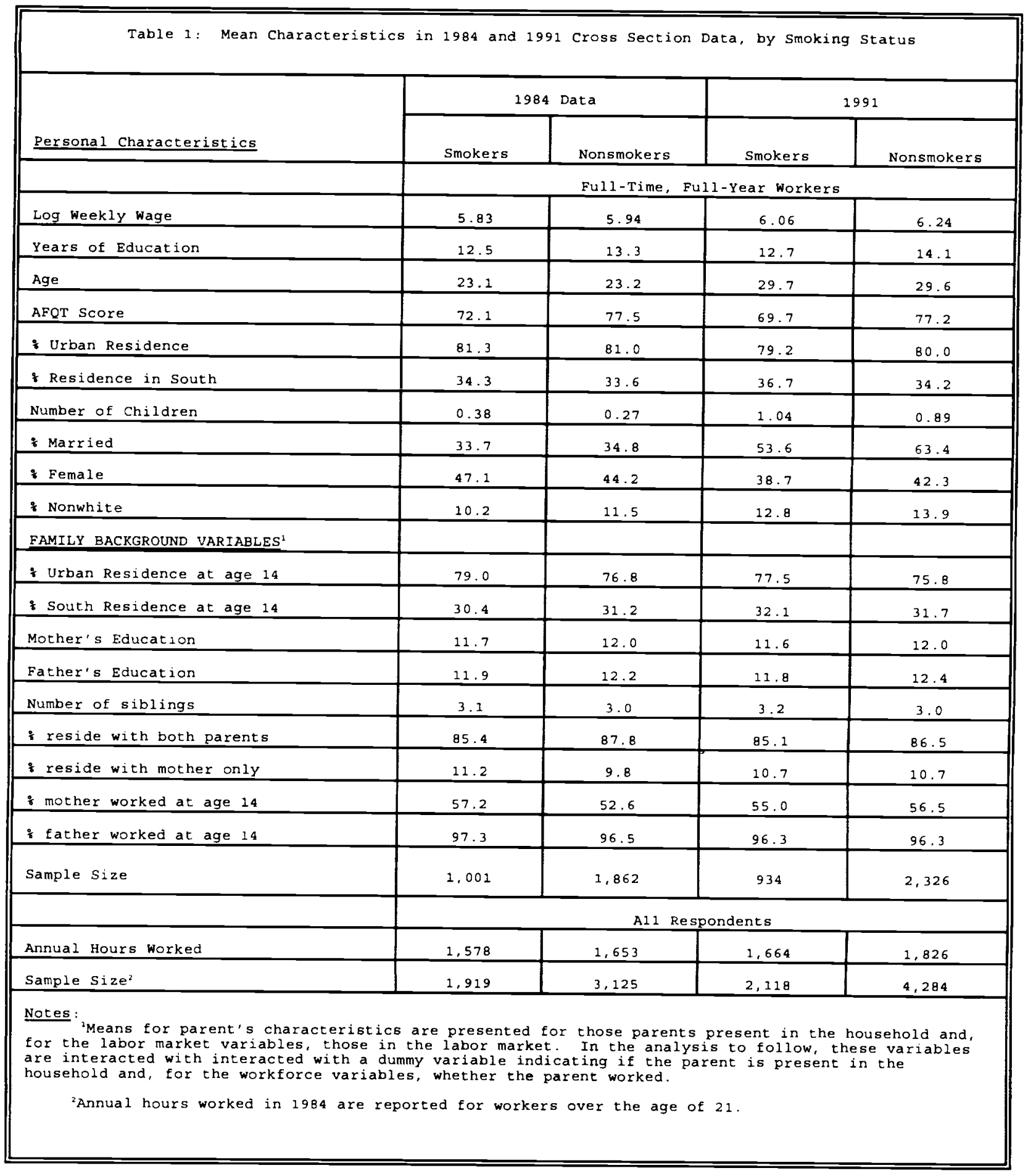




\begin{tabular}{|c|c|c|c|c|}
\hline \multicolumn{5}{|c|}{ Table 2: Mean Changes in Characteristics by Change in Smoking Behavior, $1991-1984$} \\
\hline Explanatory variables & $\begin{array}{c}\text { Continuous } \\
\text { Smokers }\end{array}$ & $\begin{array}{l}\text { Cont inuous } \\
\text { Nonsmokers }\end{array}$ & Quitters & Starters \\
\hline Change in Log weekly wage & 0.292 & 0.316 & 0.387 & 0.280 \\
\hline Change in Years of Education & 0.184 & 0.275 & 0.282 & 0.183 \\
\hline Change in Southern Residence & -0.004 & -0.001 & 0.007 & -0.033 \\
\hline Change in Urban Residence & -0.013 & 0.003 & -0.005 & 0.029 \\
\hline Change in Number of Children & 0.675 & 0.752 & 0.741 & 0.637 \\
\hline Change in Marital Status ${ }^{2}$ & 0.244 & 0.309 & 0.382 & 0.310 \\
\hline Change in Annual Hours & 98.4 & 177.7 & 15.9 & 167.9 \\
\hline Sample Size & 380 & 987 & 149 & 87 \\
\hline \multicolumn{5}{|l|}{ Notes: } \\
\hline \multicolumn{5}{|c|}{$\begin{array}{l}\text { 'Denotes number of full-time, full-year workers } \\
\text { size for all variables except for the change in } \\
\text { respondents over the age of } 22 \text { in } 1984 \text {. }\end{array}$} \\
\hline
\end{tabular}




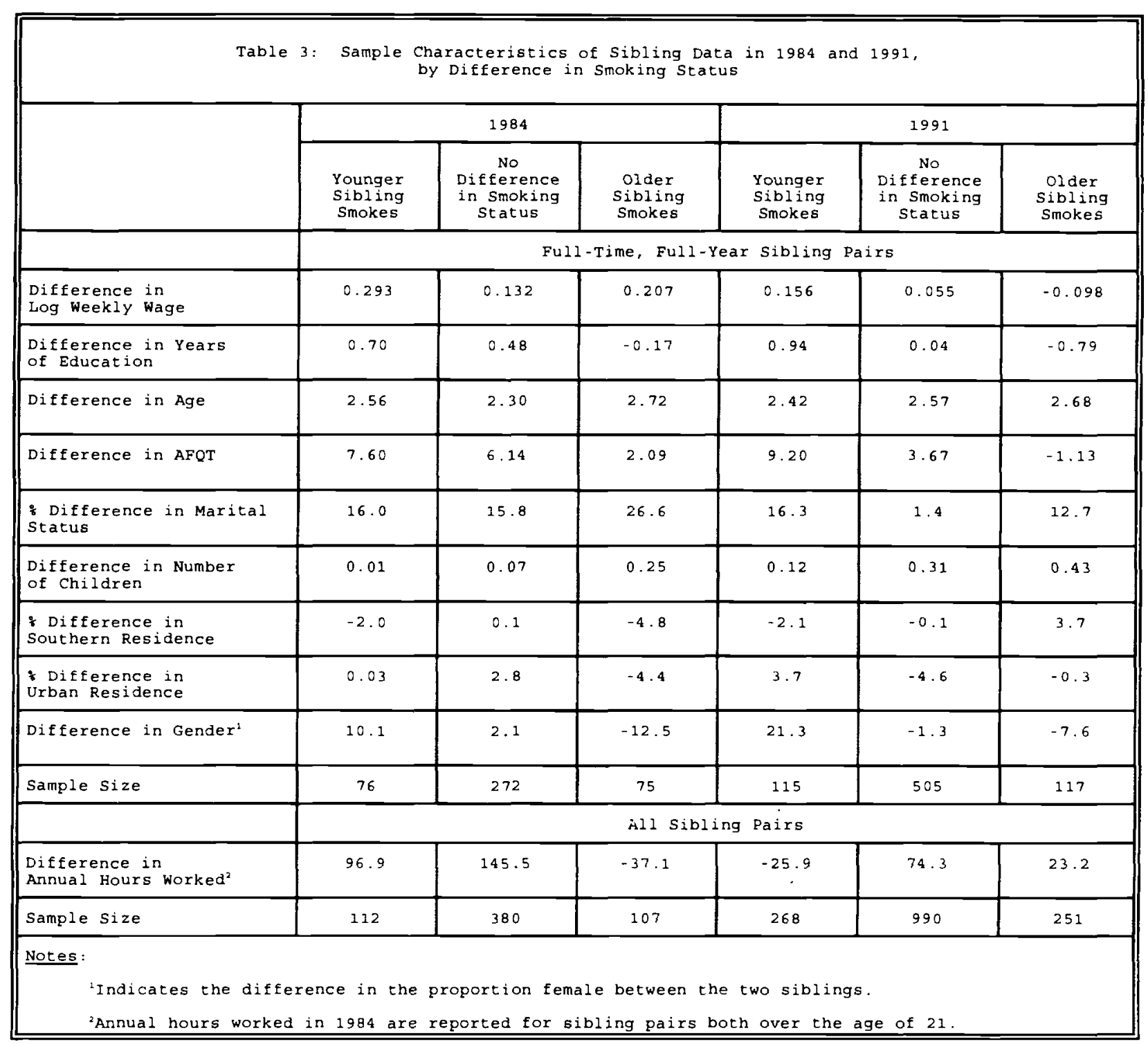




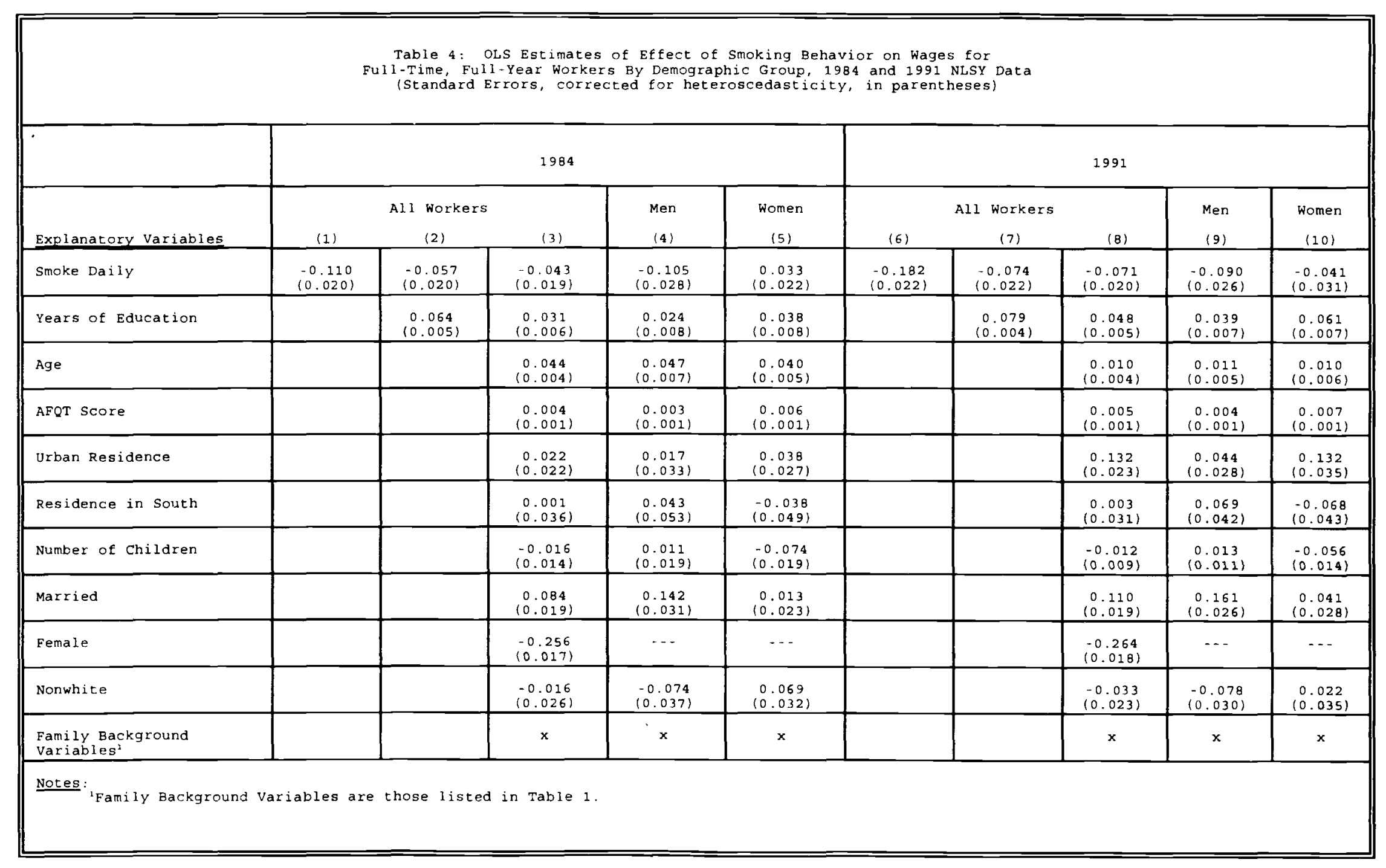




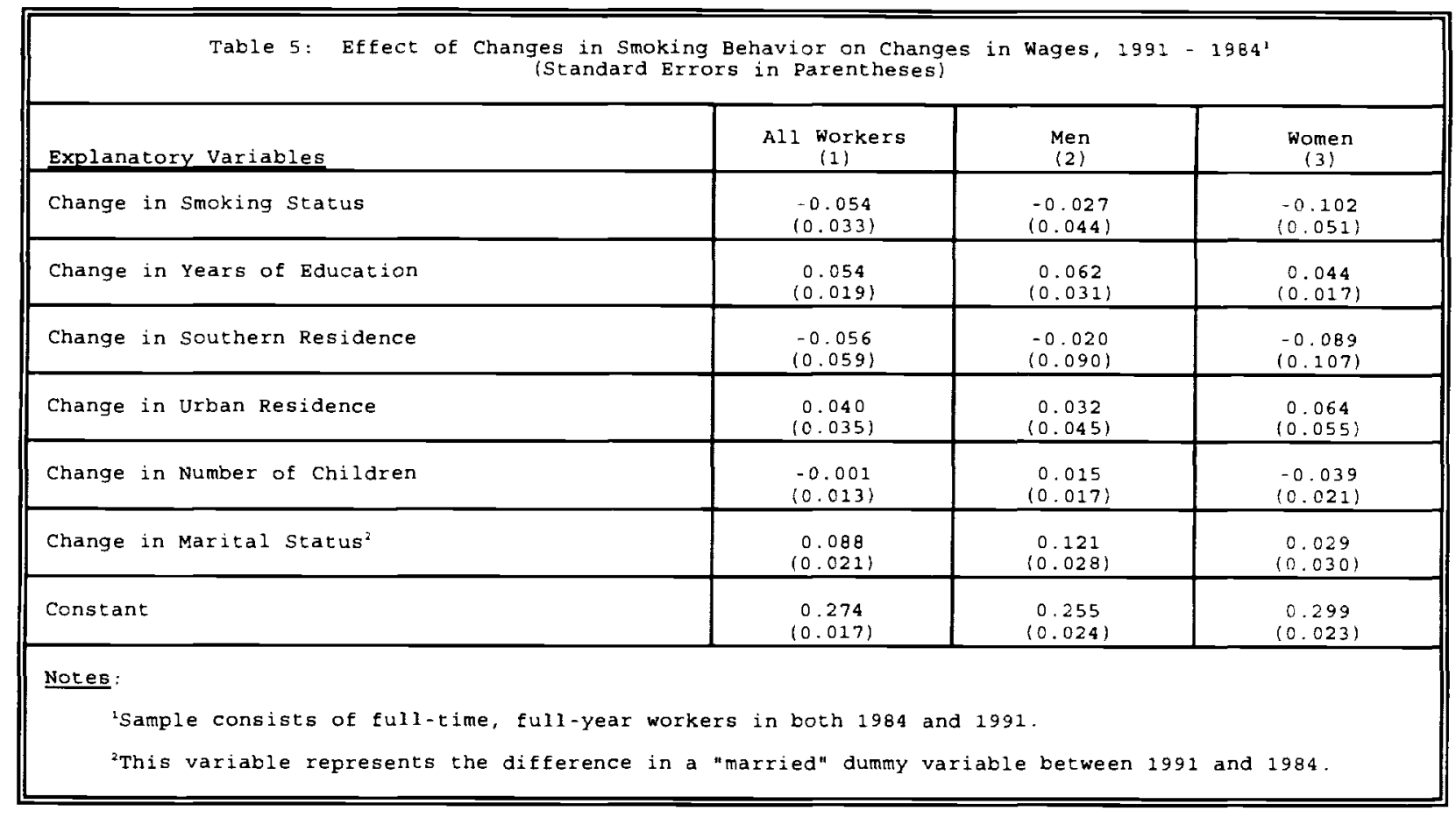




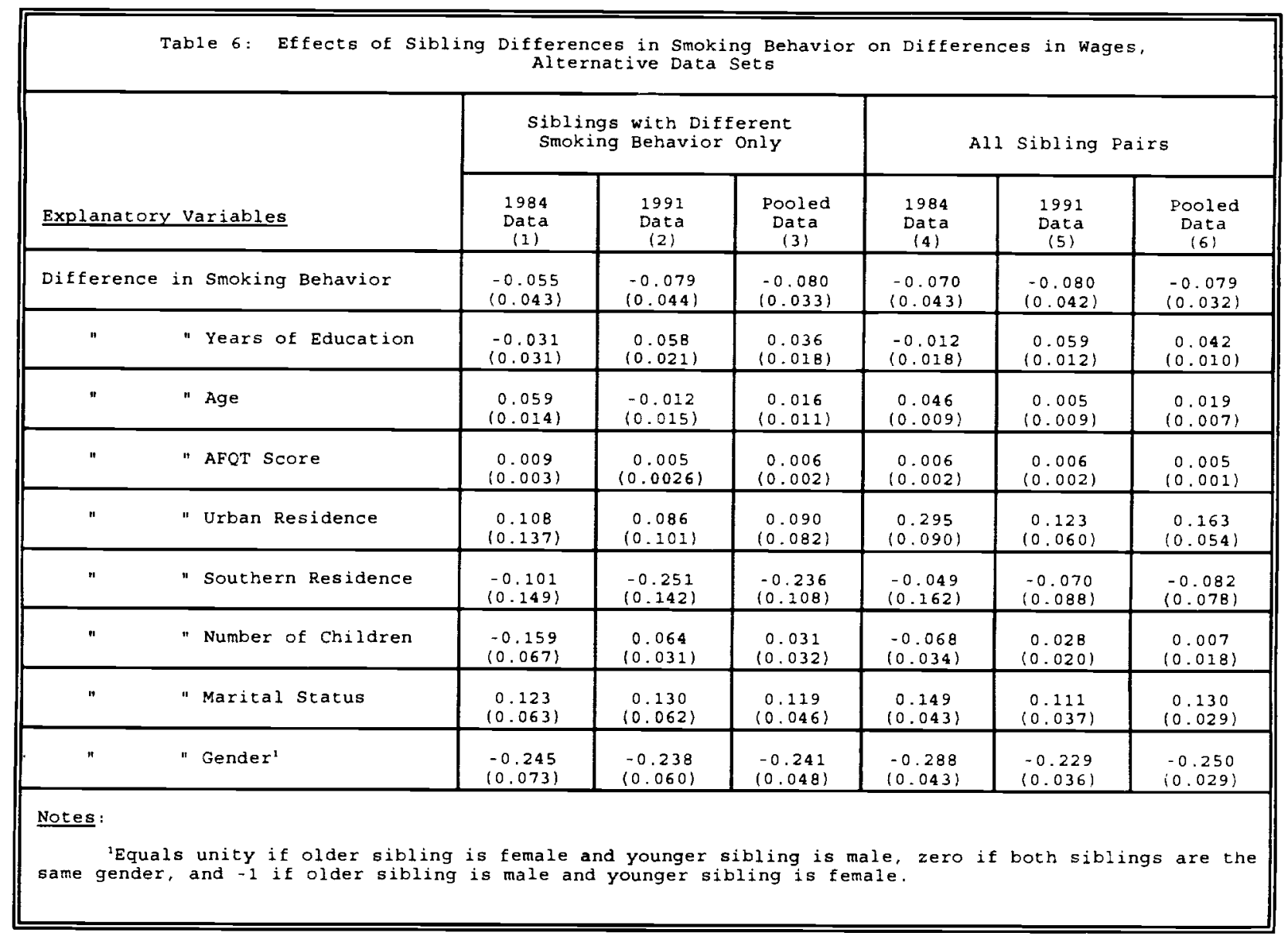




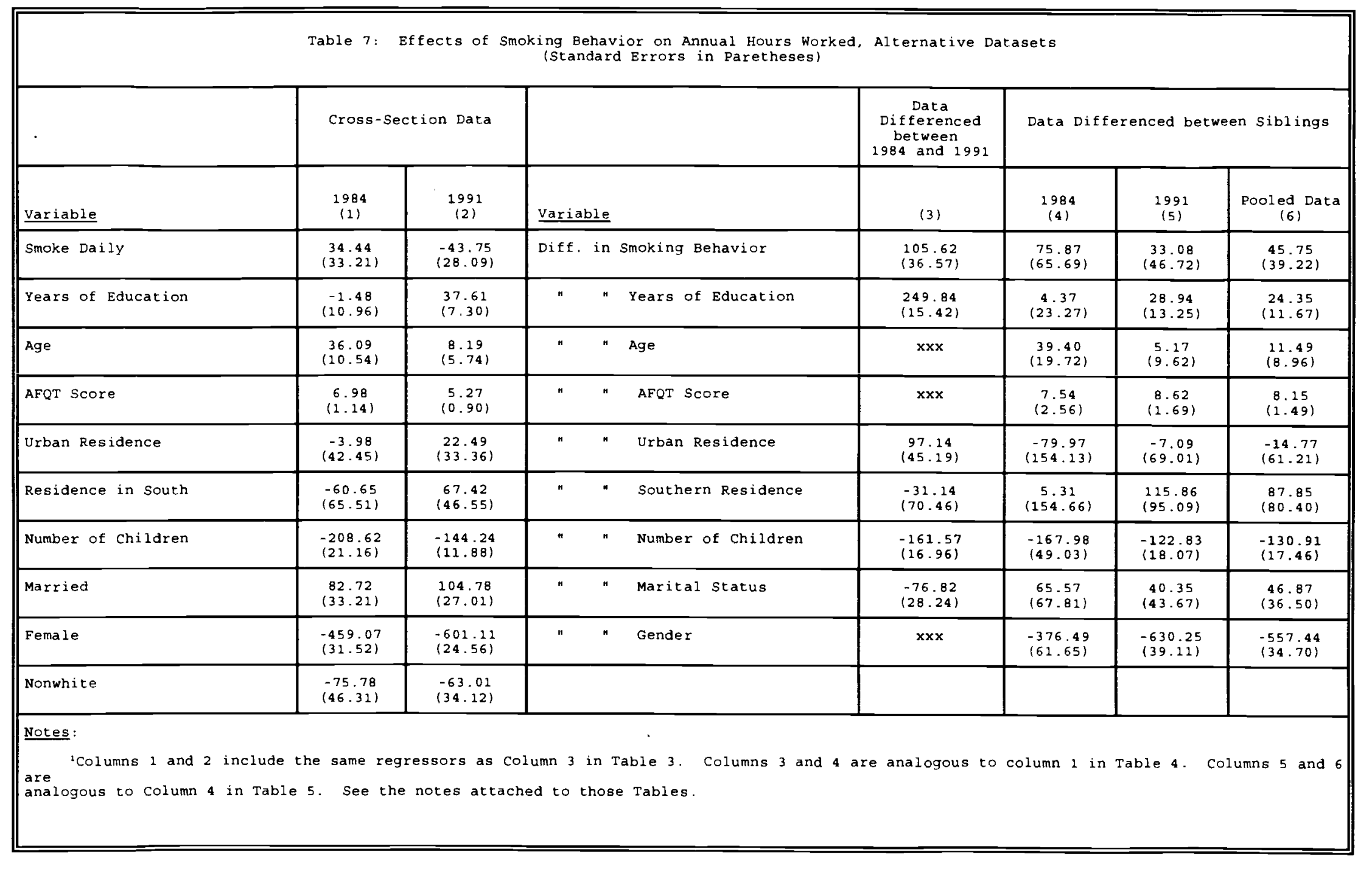

